\title{
Rosai-Dorfman disease and the heart
}

\author{
Kevin O'Gallagher*, Luke Dancy, Aish Sinha, Daniel Sado \\ Cardiology Department, King's College Hospital NHS Foundation Trust, London, UK.
}

\begin{abstract}
Summary Rosai-Dorfman disease (RDD) is a non-malignant pathology of histiocyte proliferation. The classical clinical presentation is with painless cervical lymphadenopathy, but extranodal involvement is frequent, occurring in approximately $40 \%$ of cases. The literature was systematically reviewed to identify reported cases of RDD with cardiac involvement. Eighteen cases were identified ( 3 pediatric and 15 adult). In adult cardiac RDD (cRDD), three patterns of disease were noted: an intra-cardiac mass, epicardial involvement, and pulmonary artery involvement. Reported cases suggest that surgical excision of intracardiac masses confers a good prognosis.
\end{abstract}

Keywords: Histiocytosis, non-Langerhans, cardiac

\section{Introduction}

First described in 1965 (1) and subsequently characterized in 1969 (2), Rosai-Dorfman disease (RDD) is a nonmalignant disease of histiocyte proliferation. Although the classical clinical presentation is with painless cervical lymphadenopathy (hence the alternative term "sinus histiocytosis with massive histiocytosis", or SHML), extranodal involvement is frequent, occurring in approximately $40 \%$ of cases. Common sites of extranodal involvement include the skin, nasal cavities, and paranasal sinuses. Cardiac involvement (cRDD) has previously been documented as occurring in $<0.1 \%$ of cases (3).

The etiology of RDD is as yet poorly defined and is, in the absence of convincing evidence to the contrary, currently considered to be idiopathic. A viral cause has been postulated, either via direct infection or as a result of an exaggerated immune response to the viral agent. Human herpes virus 6 (HHV6) DNA has been detected in RDD histiocytes (4), but in other cases HBV6 has not been detected (5). Epstein-Barr virus (EBV) infection has been identified in approximately half of patients

Released online in J-STAGE as advance publication February $1,2016$.

*Address correspondence to:

Dr. Kevin O'Gallagher, Cardiology Department, King's College Hospital NHS Foundation Trust, Denmark Hill, London, UK.

E-mail: k.o'gallagher@nhs.net with RDD (6), but no evidence of EBV RNA has been found in isolated RDD histiocytes or lymphocytes (7). Parvovirus B19 has been found in RDD lymphocytes (but not histiocytes) (8). A genetic form of RDD Faisalabad histiocytosis, mapped to a mutation in the SLC29A3 gene on chromosome 10q22.1 (9) - has been identified but is isolated to 3 consanguineous families.

Definitive diagnosis is by histological assessment, the two cornerstones of which are identification of emperipolesis and appropriate immunohistochemical analysis. Emperipolesis in relation to RDD refers to the presence of histiocytes containing intact lymphocytes within their cytoplasm. Emperipolesis is differentiated from phagocytosis due to the intact nature of the engulfed cell, which by definition is viable and can exit the engulfing cell without any structural or functional abnormality (10). In addition to RDD, emperipolesis is also seen in malignant disease processes, such as lymphoma, leukaemia, myelodysplasia, and myeloma. Immunohistochemical staining for S100 protein is considered diagnostic. Cells will also be positive for CD68 and negative for CD1a, helping to distinguish RDD histiocytes from Langerhans cells (11).

Management of RDD is greatly dependent on the extent and site of disease and also on the presence or absence of symptoms (12). Surgical resection is appropriate for localized disease, with radiation therapy an option for residual disease after resection. In systemic/extensive extranodal disease, first line therapy is corticosteroids. Other options include immunomodulators, and/or cytotoxic chemotherapeutic agents. Due to the infrequency of reported cases of 
cRDD, no current treatment algorithm has been defined. In general, RDD is considered a benign process, but extensive lymph node or cutaneous involvement can lead to disfigurement, and deaths have also been noted (13) (mortality 7\% (14)). RDD tends not to have an adverse prognosis unless the disease has a profound effect on vital organs or is extensive/disseminated.

\section{Literature review}

The literature was systematically reviewed (in line with PRISMA guidance) to identify cases of RDD involving the heart and/or great vessels. A search was carried out via PubMed using the terms "Rosai Dorfman" and "sinus histiocytosis" combined with "heart" and "cardiac". Only English language publications were considered. Nine hundred and forty-three results were obtained. Those results yielded 17 papers describing 18 individual cases of cRDD (Table 1). Of the 18 individual cases, 3 were pediatric cases $(<16$ years of age) while 15 were adult ( $\geq 16$ years of age).

Two of the identified papers cited an additional reported case of cRDD (15). It was, however, impossible to obtain the full text of that report, so it has been excluded from the current analysis. A further case report was also cited (16), but it has been excluded as it was not written in English.

\section{Pediatric cRDD}

Of the 3 cases of pediatric cardiac involvement in RDD, 2 had very similar presentations: young male patients with sickle cell disease, presenting with chest pain and fever. Both of these patients had a mass in the interatrial septum (IAS) with infiltration of other cardiac structures. Both patients also presented with conduction disease requiring permanent pacing. Despite the similar presentations, the subsequent course was strikingly different. Patient 1 suffered from a progressive deterioration and required a cardiac transplant, while patient 2 had an indolent course. Both patients survived. The other case of pediatric cRDD involved a 14-yearold Afro-Caribbean boy with tricuspid and pulmonary valve involvement who underwent multiple surgical interventions but who ultimately died from disease progression.

\section{Adult cRDD}

The 15 adult cases involved 10 males and 5 females ranging in age from 22-79 years (mean 49.5 years). Ethnic origin was reported for only 3 patients, making comment impossible. Three patterns were identified for the primary reported site of cardiac involvement: an intra-cardiac mass with or without underlying infiltration, pericardial/epicardial involvement, and a pulmonary arterial mass (Figure 1). Of the 15 adult

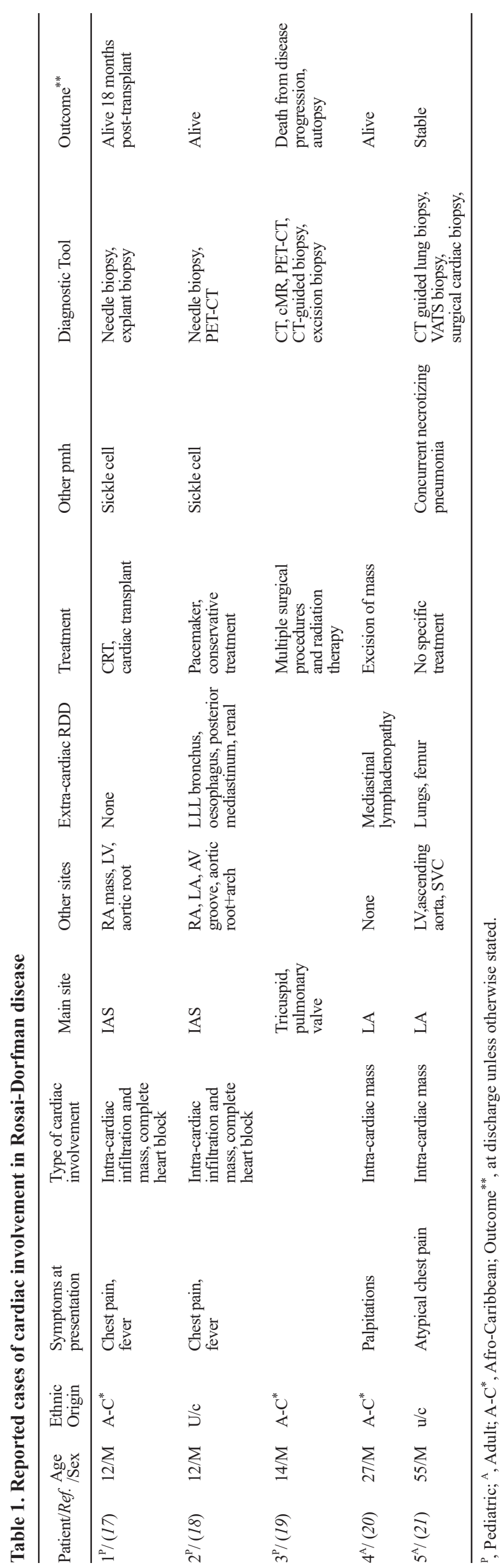




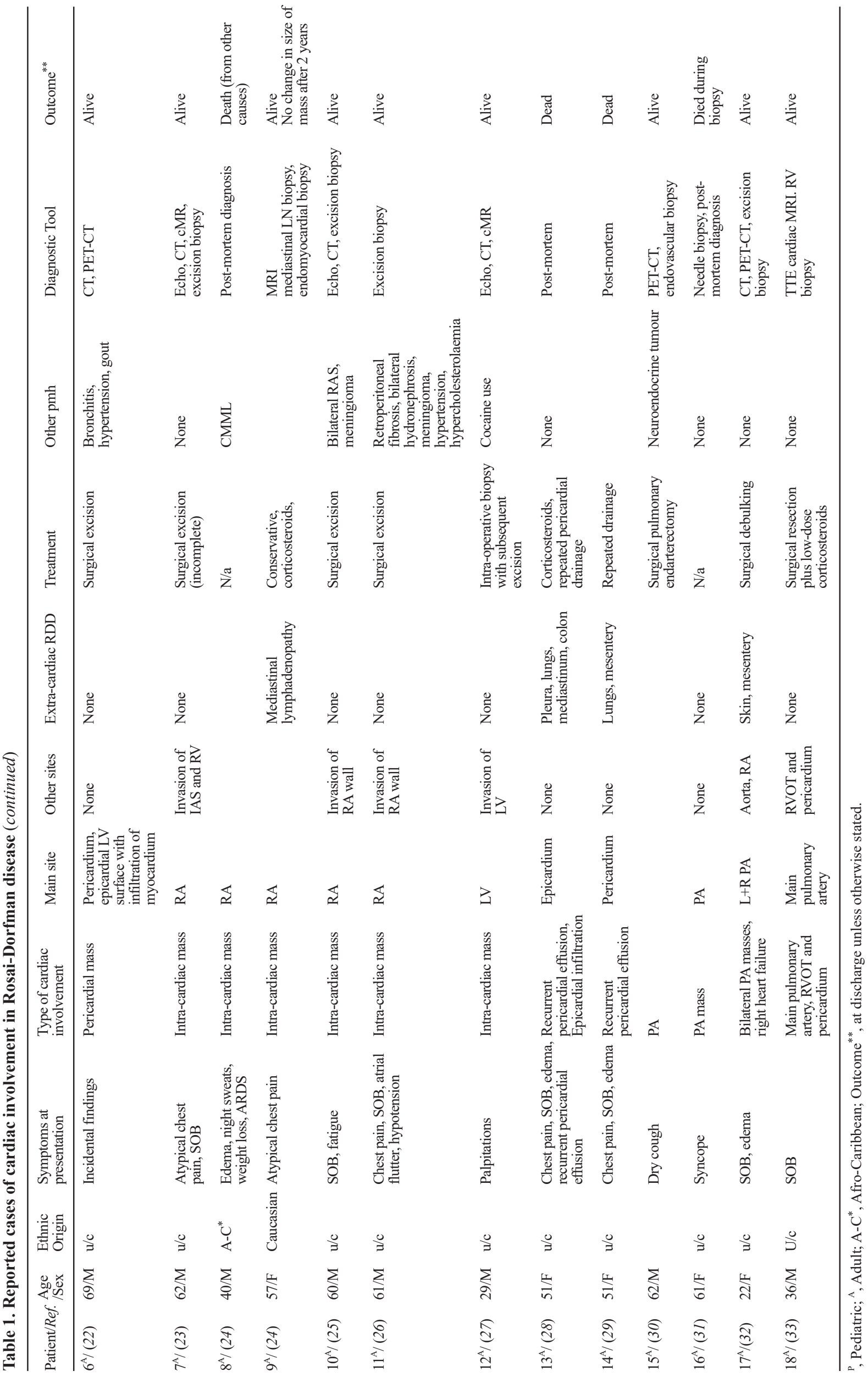




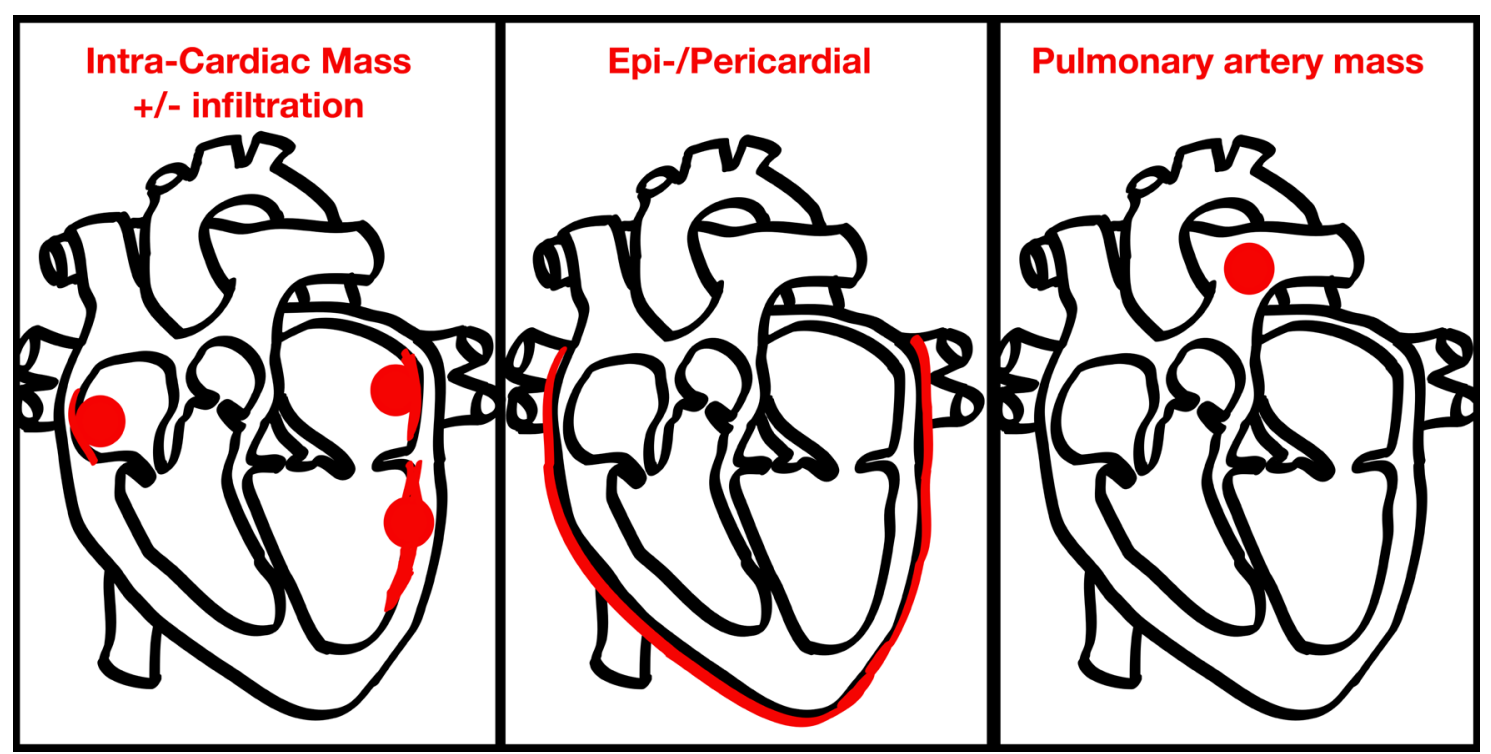

Figure 1. Patterns of cardiac involvement in adults with Rosai-Dorfman disease.

patients, 4 had pericardial/epicardial involvement, 4 had involvement of the pulmonary artery, and 9 had an intra-cardiac mass. Of those cases involving intracardiac masses, 2 had a mass in the left atrium (LA), 5 had a mass in the right atrium (RA), 1 had a mass in the left ventricle (LV), and 1 had a mass in the right ventricular outflow tract (RVOT). Seven cases presented with multi-focal cardiac involvement, i.e. invasion/extension beyond the reported primary cardiac involvement.

\section{Management of and outcomes for patients with cRDD}

Of the 15 adult patients, 3 received corticosteroid treatment. This resulted in stabilization of disease in 2 patients. The other patient who received corticosteroids died of multi-organ failure related to cRDD. Affected tissue/the mass was excised in 7 patients with good results. Of the 4 patients with PA involvement, three had a lesion that was successfully treated. The other patient died during an invasive examination.

Five deaths in the cohort (18) were reported (1 pediatric patient and 4 adults). Of the deaths, 3 were related to the cRDD itself. One patient died of other causes while 1 patient died during an invasive biopsy procedure.

\section{Discussion}

Cardiac involvement in RDD is a rare manifestation of a rare disease, occurring in $0.1-0.2 \%$ of cases. The most common mode of presentation appears to be with an intracardiac mass, which in the majority of cases represents multi-focal underlying cardiac involvement. This literature review suggests that successful surgical excision of affected tissue carries a good prognosis.
This literature review has two main limitations. First, it relies on case reports, so there is very limited information on the subsequent follow-up of the patients involved. Thus, no comment can be made on the long-term clinical course, or indeed the frequency of disease recurrence in patients. Second, the condition is rare, so there are likely to be cases that have yet to be diagnosed, either due to unfamiliarity with the disease or due to lack of access to appropriate examinations.

\section{References}

1. Destombes P. Adenitis with lipid excess, in children or young adults, seen in the Antilles and in Mali (4 cases). Bull Soc Pathol Exot Filiales. 1965; 58:1035-1039. (in French)

2. Rosai J, Dorfman RF. Sinus histiocytosis with massive lymphadenopathy. A newly recognized benign clinicopathological entity. Arch Pathol. 1969; 87:63-70.

3. Gaitonde S. Multifocal, extranodal sinus histiocytosis with massive lymphadenopathy: An overview. Arch Pathol Lab Med. 2007; 131:1117-1121.

4. Levine PH, Jahan N, Murari P, Manak M, Jaffe ES. Detection of human herpesvirus 6 in tissue involved by sinus histiocytosis with massive lymphadenopathy (RosaiDorfman disease). J Infect Dis. 1992; 166:291-295.

5. Ortonne N, Fillet AM, Kosuge H, Bagot M, Frances C, Wechsler J. Cutaneous Destombes-Rosai-Dorfman disease: Absence of detection of HHV-6 and HHV-8 in skin. J Cutan Pathol. 2002; 29:113-118.

6. Foucar E, Rosai J, Dorfman R. Sinus histiocytosis with massive lymphadenopathy (Rosai-Dorfman disease): Review of the entity. Semin Diagn Pathol. 1990; 7:19-73.

7. Tsang WY, Yip TT, Chan JK. The Rosai-Dorfman disease histiocytes are not infected by Epstein-Barr virus. Histopathology. 1994; 25:88-90.

8. Mehraein Y, Wagner M, Remberger K, Füzesi L, Middel P, Kaptur S, Schmitt K, Meese E. Parvovirus B19 detected in Rosai-Dorfman disease in nodal and extranodal manifestations. J Clin Pathol. 2006; 59:1320-1326. 
9. Morgan NV, Morris MR, Cangul $\mathrm{H}$, et al. Mutations in $S L C 29 A 3$, encoding an equilibrative nucleoside transporter ENT3, cause a familial histiocytosis syndrome (Faisalabad histiocytosis) and familial Rosai-Dorfman disease. PLoS Genet. 2010; 6:e1000833.

10. Humble JG, Jaynee WHM, Pulvertaft RJ. Biological interaction between lymphocyte and other cells. Br J Hematol. 1956; 2:283.

11. Rastogi V, Sharma R, Misra SR, Yadav L, Sharma V. Emperipolesis - A review. J Clin Diagn Res. 2014; 8:ZM01-2.

12. Dalia S, Sagatys E, Sokol L, Kubal T. Rosai-Dorfman disease: Tumor biology, clinical features, pathology, and treatment. Cancer Control. 2014; 21:322-327.

13. Foucar E, Rosai J, Dorfman RF. Sinus histiocytosis with massive lymphadenopathy. An analysis of 14 deaths occurring in a patient registry. Cancer. 1984; 54:18341840.

14. Liu L, Perry AM, Cao W, Smith LM, Hsi ED, Liu X, Mo JQ, Dotlic S, Mosunjac M, Talmon G, Weisenburger DD, Fu K. Relationship between Rosai-Dorfman disease and IgG4-related disease: Study of 32 cases. Am J Clin Pathol. 2013; 140:395-402.

15. Halabe-Cherem J, Cuan-Perez M, Wacher N. A case of sinusoidal histiocytosis with possible invasion of the heart. Rev Med Inst Mex Seguro Soc. 1988; 26:295-298.

16. Scheffel H, Vogt $\mathrm{P}$, Alkadhi H. Cardiac manifestations of Rosai-Dorfman disease. Herz. 2006; 31:715-716. (in German)

17. Schaffer LR, Caltharp SA, Milla SS, Kogon BF, Cundiff CA, Dalal A, Quigley PC, Shehata BM. Rare presentation of four primary pediatric cardiac tumors. Cardiovasc Pathol. 2016; 25:72-77.

18. Yontz L, Franco A, Sharma S, Lewis K, McDonough C. A case of Rosai-Dorfman disease in a pediatric patient with cardiac involvement. J Radiol Case Rep. 2012; 6:1-8.

19. Buchino JJ, Byrd RP, Kmetz DR. Disseminated sinus histiocytosis with massive lymphadenopathy: Its pathologic aspects. Arch Pathol Lab Med. 1982; 106:13-16.

20. Daruwalla VJ, Parekh K, Tahir H, Collins JD, Carr J. Extranodal Rosai-Dorfman disease involving the left atrium: Cardiac MRI, CT, and PET scan findings. Case Rep Radiol. 2015; 2015:753160.

21. Richter JT, Strange RG Jr, Fisher SI, Miller DV, Delvecchio DM. Extranodal Rosai-Dorfman disease presenting as a cardiac mass in an adult: Report of a unique case and lack of relationship to IgG4-related sclerosing lesions. Human Pathol. 2010; 41:297-301.

22. Lao IW, Dong Y, Wang J. Rosai-Dorfman disease of the pericardium: A case report and review of literature. Int $\mathrm{J}$ Clin Exp Pathol. 2014; 7:3408-3412.

23. Özbudak E, Arıkan AA, Yavuz S, Halıcı U, Berki T. A very rarely seen cardiac mass (Rosai-Dorfman disease). Anadolu Kardiyol Derg. 2014; 14:475-483.

24. Maleszewski JJ, Hristov AC, Halushka MK, Miller DV. Extranodal Rosai-Dorfman disease involving the heart: Report of two cases. Cardiovasc Pathol. 2010; 19:380384.

25. Bi Y, Huo Z, Meng Y, Wu H, Yan J, Zhou Y, Liu X, Song L, Lu Z. Extranodal Rosai-Dorfman disease involving the right atrium in a 60-year-old male. Diagn Pathol. 2014; 9:115.

26. Ajise OE, Stahl-Herz J, Goozner B, Cassai N, McRae G, Wieczorek R. Extranodal Rosai-Dorfman disease arising in the right atrium: A case report with literature review. Int J Surg Pathol. 2011; 19:637-642.

27. Sarraj A, Zarra KV, Jimenez Borreguero LJ, Caballero $\mathrm{P}$, Nuche JM. Isolated cardiac involvement of RosaiDorfman disease. Ann Thorac Surg. 2012; 94:2118-2120.

28. Chen J, Tang H, Li B, Xiu Q. Rosai-Dorfman disease of multiple organs, including the epicardium: An unusual case with poor prognosis. Heart Lung. 2011; 40:168-171.

29. Da Xu J, Cao XX, Liu XP, Li QQ, Wang WJ, De Xu Z. Hydropericardium prevented diagnosis of constrictive pericarditis: An unusual case of Rosai-Dorfman disease. BMJ Case Rep. 2009; pii: bcr03.2009.1688.

30. Morsolini M, Nicola M, Paulli M, D'Armini AM. Primary pulmonary artery Rosai-Dorfman disease mimicking sarcoma. J Thorac Cardiovasc Surg. 2013; 146:e57-e59.

31. Rehman T, deBoisblanc BP, Kantrow SP. Extranodal Rosai-Dorfman disease involving the pulmonary artery. Eur J Cardiothorac Surg. 2013; 44:964.

32. Walters DM, Dunnington GH, Dustin SM, Frierson HF, Peeler BB, Kozower BD, Ailawadi G, Jones DR, Lau CL. Rosai-Dorfman disease presenting as a pulmonary artery mass. Ann Thorac Surg. 2010; 89:300-302.

33. Chaitanya V, Gupta N. Isolated cardiac involvement of extranodal Rosai-Dorfman disease: An atypical presentation. J Cardiol Curr Res. 2015; 3:99.

(Received December 19, 2015; Revised January 7, 2016; Accepted January 17, 2015) 